\title{
Moving Learning and Teaching in Higher Education (LTHE) online: can we have the cake and eat it too?
}

Giorgia Pigato,

The University of Exeter, UK

Keywords: Covid-19; Teaching Assistants training; online professional development; online communities of learning.

\section{The challenge}

The Academic Development team design and deliver the Learning and Teaching in Higher Education (LTHE) course at the University of Exeter. The course is aimed at postgraduates who intend to work as teaching assistants, educators on research-only contracts, and professional services staff who facilitate learning. It is mandatory for postgraduates who teach (PTAs). Prior to March 2020 LTHE consisted of: Stage 1, a full day workshop, and Stage 2, four half-day sessions, all delivered face-to-face. Typically, around 300 students per academic year engaged with the course.

In 2020 we had to re-design the entire course to be online by early September. A specific challenge for this type of course is that, although attending LTHE is great for development and opens work opportunities, it is rarely a priority for participants whose focus is either on their $\mathrm{PhD}$ or full-time employment.

Lack of time and resources affected some of the choices we made and a project that would usually have taken at least a year was put together in a few months. We had to guarantee the high-quality pedagogy of the previous years but in a completely new mode. We needed to make sure that we did not try to replicate face-to-face teaching models but took advantage of the benefits that flexible delivery could offer.

- We met the specific needs of educators new to teaching in $\mathrm{HE}$. 
- We gave participants an understanding of how to provide an active, stimulating, student-centred learning experience.

- Participants had opportunities to reflect.

- We did all of this using a learner-centred approach.

Having a sense of belonging, relationship building, and trust strongly influence learner emotions (McGill, Beetham and Gray, 2016); therefore we wanted to foster a sense of community, support, and compassion, especially because many participants are in the early stages of their careers.

\section{The response}

Because online teaching is not simply moving your existing content onto a VLE, we redesigned the course following the university Learning Model, especially created for the move online and inspired by ABC Learning Design (ABC-ld.org). We aimed at offering maximum flexibility and ease of access to all and we decided that:

- Students could enrol any time and could proceed at their own pace.

- There would be opportunities to get to know each other and collaborate, for example, by adopting icebreakers and tools such as an online forum, Menti, Padlet, and Notebook.

- The tutors recorded short, informal videos to make the approach more personal and welcoming.

- We also added regular short quizzes so that students could check their learning, and we could keep track of engagement.

A priority for us at all times was expressing empathy in the virtual environment via announcements, posts, and videos as we felt it created a bond between staff and student in these exceptional and isolating circumstances (Brown and McCall, 2021). These tools foster engagement and peer discussion, and they afford variety as well. But also, the programme allows participants to test these digital tools and choose those appropriate to their teaching context. 


\section{What was the feedback?}

One major advantage was how inclusive online delivery was. We believe this is the reason behind increased enrolment. Participation is very high; we now have 545 registrations compared to 300 in a regular year. The end of course feedback was also very positive: 4.03 out of 5 which is in line with previous years.

Participants noted that they had signed up for the course previously but then had been unable to attend or finish it because of other commitments. Most commented that picking up the course anytime they wanted was invaluable. And some said they thought the flexibility was great, but they missed being with people and were afraid of becoming too accustomed to work on their own, with one comment being: 'I guess we want to have the cake and eat it!' Mid-way through the year, the students' feedback was that they missed live interaction and meeting others. We decided to set-up optional Teams meetings, with the aim of getting people together. We had some prompts for discussion but planned to have breakout rooms where participants could get to know each other and talk freely. These were widely advertised but, to our great surprise, very few people participated. We had to assume that participants, like everybody else, had to be selective in what to attend, and that they did not want to engage online all the time. This is an area we intend to explore further in the coming academic year. The variety of tools and the tutors' videos were also highly rated.

\section{Recommendations}

We cannot stress enough how much this category of students appreciated the flexibility afforded by this format and therefore we will not go back to total in-person delivery. This experience has given us the chance to reflect on flexible practice, revisit ways that learning communities can support each other, and reconsider what teaching face-to-face means as well as our role as developers and tutors. We are still in the process of finalising the course for next year but, so far, this is what we are planning:

We will deliver most of the course asynchronously, in particular the compulsory sections. However, we will also offer synchronous sessions, some online and some in person, as this is something noted in the feedback. To cite Brown and McCall: 'meaningful human 
interaction is the foundation stone of all positive educational practice' (2021, pp.5-9). We want the students to become more autonomous, but we still have limited resources. To achieve this we will offer more structure at the start, help them to set goals, and make and monitor plans. This is especially important when entering a new or different learning context and we should make clearer how they could engage in learning (Macaskill and Taylor, 2010). We have created a list of essential and possible changes and we will follow these criteria based on capacity. We are also exploring joining forces with other staff and delivering fewer, longer tutorials to a wider audience. We aim to create more opportunities for meaningful dialogue and feedback, and be proactive in seeking communication, utilising live meetings and other check in opportunities. After all, regular catch ups with supportive tutors are key to motivation (McGill, Beetham and Gray, 2016). This might not be attainable straight away; we hope that the tweaks mentioned above will help us strike a balance between interaction, convenience of asynchronous study, and limited resources.

Online learning can, without a doubt, remove many barriers to learning, especially time and geography barriers (Burge, Campbell Gibson and Gibson, 2011) but we should not assume all challenges are resolved because of it. Now, even more than before, we will strive to deliver pedagogy that is suitable for any mode and for all.

\section{References}

ABC Learning Design, Sprint design your courses and programs in just 90 minutes. Available at: https://abc-ld.org (Accessed: 10 September 2021)

Brown, G. and McCall, V. (2021) 'Community, adaptability, and good judgement: Reflections on creating meaningful, sustainable pedagogy in uncertain times', Developing Academic Practice, pp. 5-9. https://doi.org/10.3828/dap.2021.3.

Burge, E., Campbell Gibson, C. and Gibson, T. (2011) Flexible pedagogy, flexible learning: notes from the trenches of distance education. Edmonton: AU Press.

Macaskill, A. and Taylor, E. (2010) 'The development of a brief measure of learner autonomy in university students', Studies in Higher Education, 35(3), pp.351-359. http://doi.org/10.1080/03075070903502703. 
McGill, L., Beetham, H. and Gray, T. (2016) What makes a successful online learner?

Findings of the Digital Student Online learners' expectations and experiences of the digital environment. Available at:

https://www.qub.ac.uk/directorates/media/Media,992744,smxx.pdf (Accessed: 15 August 2021)

\section{Author details}

Giorgia Pigato (FHEA) is an Associate Academic Developer at the University of Exeter where she is the module lead for LTHE and supports best practices in teaching. She has been teaching pedagogy and foreign languages for over 20 years in a wide range of educational settings. 